\title{
In situ Visualization of Water Droplets in Polymer Electrolyte Fuel Cell Cathode
}

\author{
Toshiaki Murahashi, ${ }^{*}$ Hiroyuki Kobayashi, and Enju NishiYama
}

\begin{abstract}
Department of Electrical and Electronic Engineering, Fukui University of Technology (Gakuen 3-6-1, Fukui 9108505, Japan)

Received August 19, 2006 ; Accepted September 21, 2006

A transparent optical cell for a polymer electrolyte fuel cell (PEFC) was used to measure the water distribution in the cathode during cell operation. The distribution of water droplets could be clearly observed in the cathode. The results show that the transition point to two-phase flow in the cathode flow field moved towards the cathode inlet when the cathode gas utilization rate was increased. This was compared with the results of a calculation based on a two-dimensional cell model and good agreement between the two was obtained. It was also observed that at high current densities, water droplets were swept away from the flow field by the shear force of the cathode gas.
\end{abstract}

Key Words : Visualization, Water Droplet, Water Transport, Flooding

\section{Introduction}

In the field of water management research, many studies of water transport, especially modeling ${ }^{1-3)}$ of twophase flow, have been extensively carried out. By contrast, experimental studies lag significantly behind the modeling work that has been done. The reason for this lag is mainly due to the difficulty of monitoring water transport inside a cell in experiments. Recently, powerful methods for monitoring water transport have been developed. These include an optical method ${ }^{4,5}$ and a neutron radiography method. ${ }^{6}$ )

Neutron radiography imaging has the potential to measure the water content of each component in a cell. However, this technique currently has limited spatial and temporal resolutions. The optical visualization method, on the other hand, has much better spatial and temporal resolutions. Tüber et al. ${ }^{4}$ studied the water behavior in a cell and correlated it with the cell performance, although the experimental conditions (for example, cell temperature) they employed varied from those of systems currently being tested. Wang et al. ${ }^{5,7)}$ studied the characteristics of the two phase flow of water and they observed in detail the dynamics of the life cycle of a water droplet. However, they reported mainly the movement of water droplets from flow dynamics and did not present a whole cell image of the water droplets. The aim of this present study was to design and operate a cell having specifications as close as possible to those of systems currently being tested and to carry out in situ visualization of water droplets in the whole cell, while simultaneously measuring the cell performance characteristics.

\section{Experimental}

A new cell was designed to optically observe the distribution of liquid water droplets in the cathode. ${ }^{8,9)}$ The utilization rates of the reactant gases were $70 \%$ at the anode and $50 \%$ at the cathode; these were the standard operating conditions used in the present study.

The cell active area was $25 \mathrm{~cm}^{2}$ and a counter-flow configuration was employed. Hydrogen and air were used as the reactant gases. The membrane electrode assembly (MEA) consisted of a membrane (Nafion 112) and electrodes and carbon-paper-type gas diffusion layers (GDLs) were used. The catalyst loading level was 0.3 $\mathrm{mg} / \mathrm{cm}^{2}$ for the anode and $0.5 \mathrm{mg} / \mathrm{cm}^{2}$ for the cathode. The dew point of the reactant gases at the inlet was $65^{\circ} \mathrm{C}$ for both the anode and the cathode. The cell voltage, internal resistance and oxygen gain were measured simultaneously by optical observation. Images were acquired using a high resolution digital camera (Canon EOS 10D).

The cell temperature was $70{ }^{\circ} \mathrm{C}$ and a water jacket, in which hot water was circulated in order to maintain an even temperature distribution, was set on the back of the anode end plate. To observe the water droplets clearly, the cell was placed in an electric oven to prevent the transparent end plate from fogging. The cell temperature was controlled at $70{ }^{\circ} \mathrm{C} \pm 0.5{ }^{\circ} \mathrm{C}$.

\section{Results and Discussion}

3. 1 Cathode gas utilization rate and water droplet distribution

In the measurements performed in this study, the cell performances were measured at a current density of 0.3 $\mathrm{A} / \mathrm{cm}^{2}$, a cell temperature of $70{ }^{\circ} \mathrm{C}$ and a hydrogen utilization rate (Uf) of $70 \%$, while the oxygen utilization rate (Uo) was varied. As Fig.1 shows, a cell voltage of $0.73 \mathrm{~V}$ was achieved, indicating that the optical cell performs well. Figure 2 shows photographs of the water droplets in the cathode for three different oxygen utilization rates. In each photograph, the first droplet observed in the flow field is marked with a circle. Figures 1 and 2 show that (1) oscillations of the cell voltage were 
observed when the cathode gas utilization rate was increased; (2) the oxygen gain increased from $80 \mathrm{mV}$ to $116 \mathrm{mV}$ when the gas utilization rate was increased; (3) the distribution of water droplets moved toward the cathode inlet when the cathode gas utilization rate was increased.

The circle indicates the transition point from singlephase flow (water vapor) to two-phase flow (mixed flow of water vapor and liquid), which occurs when the water vapor pressure reaches the saturation pressure at the cell temperature. The point $x_{\text {cond }}$ at which condensation starts was calculated using a cell model and this value was compared with the transition point measured in the experiments. The left hand side of Eq. (1) represents the cumulative water transport to the cathode in the area between the inlet and $x_{\text {cond. }}$.

$$
\int_{0}^{x_{\text {cond }}} \frac{I(x)}{2 F}(1+2 \alpha(x)) d x=m_{H z o, ~ s a t}-m_{H z O, \text { in }}
$$

where $I$ is the current density, $\alpha$ is the net drag of water per proton, $x$ is the coordinate along the gas flow direction, $m_{\mathrm{H}_{2} \mathrm{O}}$ denotes the molar flow rate of the cathode water vapor. The results are shown in Fig.3. While the calculated points are slightly closer to the cathode outlet in the flow channel compared to the experimentally mea-

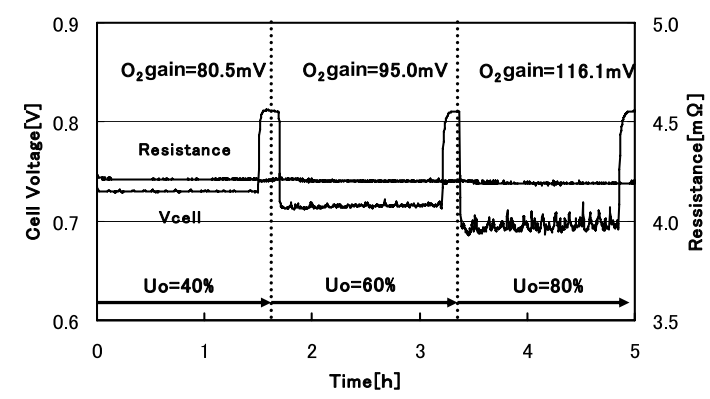

Fig. 1 Cell performance and air utilization rate. Current density: $0.3 \mathrm{~A} / \mathrm{cm}^{2}, \mathrm{H}_{2} /$ air, Uf: $70 \%$, Cell temperature: $70^{\circ} \mathrm{C}$. $\mathrm{H}_{2}$ and air humidification temperature: $\mathrm{Tda}=\mathrm{Tdc}=65^{\circ} \mathrm{C}$, $\mathrm{O}_{2}$ gain $=\mathrm{Vcell}\left(\mathrm{O}_{2}\right)-\mathrm{V}$ cell(air) sured points, in general they are in good agreement. The details of the two-dimensional cell model used in this study, including the current density distribution and the net drag along the flow channel, are described elsewhere.9)

\section{2 Current density and distribution of water droplets}

Measurements of the cell performance, the internal resistance and the oxygen gain were performed in parallel with recording images of the water droplets when the

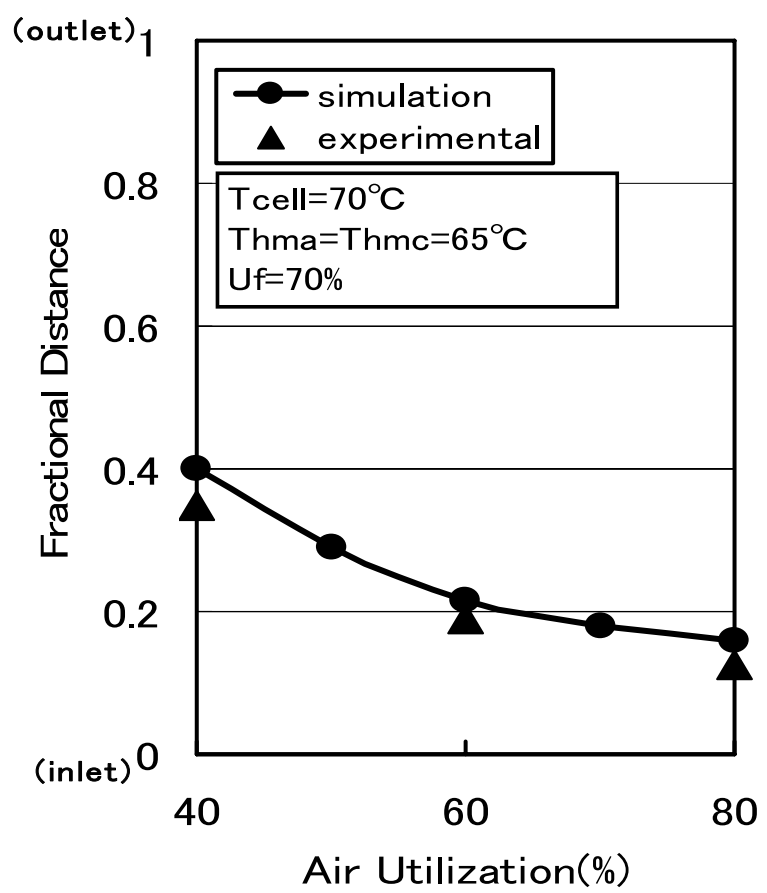

Fig. 3 Comparison of transition point to two-phase flow between the experimental results and simulation results. The locations where the liquid water droplet was observed first in the cathode flow channel are circled. Current density: $0.3 \mathrm{~A} / \mathrm{cm}^{2}, \mathrm{H}_{2} /$ air, Uf: $70 \%$, Cell temperature: $70{ }^{\circ} \mathrm{C}$. $\mathrm{Tda}=\mathrm{Tdc}=65^{\circ} \mathrm{C}$, (a) $\mathrm{Uo}=40 \%$, (b) $\mathrm{Uo}=60 \%$, (c) $\mathrm{Uo}=80 \%$

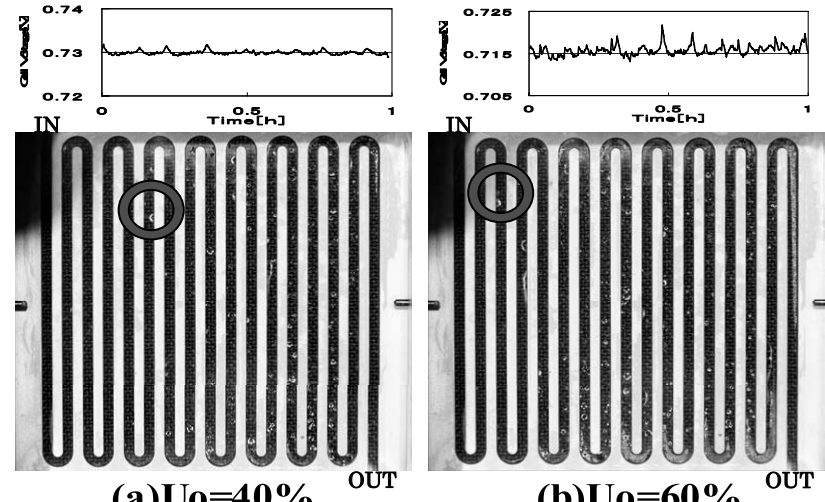

(a) $\mathrm{Uo}=\mathbf{4 0} \%$ (b) $\mathrm{Uo}=60 \%$

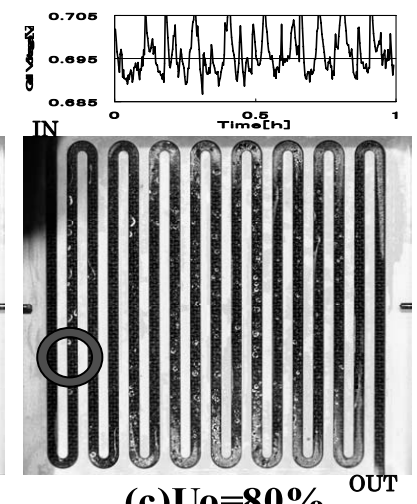

(c) $\mathrm{Uo}=\mathbf{8 0} \%$

Fig. 2 Visualized water droplets and air utilization rate. Upper graphs show the oscillations of cell voltage with time. Current density: $0.3 \mathrm{~A} / \mathrm{cm}^{2}, \mathrm{H}_{2} /$ air, Uf: $70 \%$, Cell temperature: $70^{\circ} \mathrm{C}$. $\mathrm{Tda}=\mathrm{Tdc}=65^{\circ} \mathrm{C}$, (a) $\mathrm{Uo}_{0}=40 \%$, (b) $\mathrm{Uo}=60 \%$, (c) $\mathrm{Uo}=80 \%$. 
current density was varied from $0.3 \mathrm{~A} / \mathrm{cm}^{2}$ to $0.9 \mathrm{~A} / \mathrm{cm}^{2}$ (Fig.4). Figure 5 shows the distribution of water droplets measured at the same time as the cell performance measurements. Figures 4 and 5 show that (1) the oxygen gain increased from $76 \mathrm{mV}$ to $112 \mathrm{mV}$; (2) oscillations of the cell voltage were observed when the current density was increased; (3) at $0.6 \mathrm{~A} / \mathrm{cm}^{2}$, the number of droplets decreased and the transition point moved toward the cathode outlet; (4) at $0.9 \mathrm{~A} / \mathrm{cm}^{2}$, no water droplets were observed in the cathode GDL.

The shift of the transition point is explained as follows. The peak of the current density in the cell moves towards the outlet (i.e. the wetter cathode region), since the pressure losses of the reactant gases due to diffusion in the GDL and the MEA increase at higher current densities. This movement toward the outlet agrees with the model calculation, but the point is relatively close to the outlet because of the high flow velocity. This agrees with the results obtained by Wang et al., ${ }^{7)}$ who measured the critical gas velocity for the detachment of water droplets.

The reason why no water droplets were observed at $0.9 \mathrm{~A} / \mathrm{cm}^{2}$ is considered to be the shear force created by the high gas velocity, which blows the water droplets toward the outlet. However, the results at high current densities do not imply that there is no flooding in the cathode. It is important to understand that flooding actu-

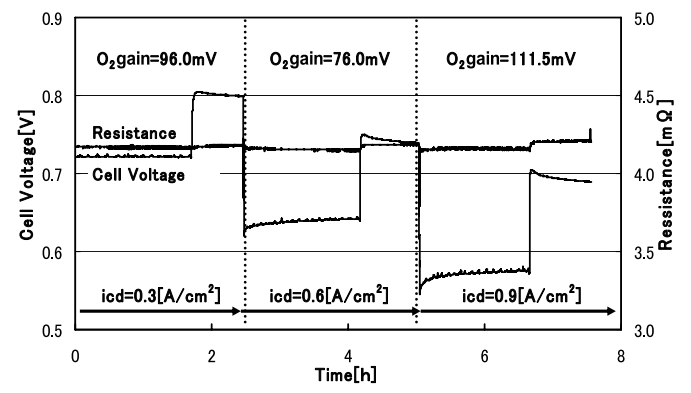

Fig. 4 Cell performance and current density. $\mathrm{H}_{2}$ /air, Uf: $70 \%$, Uo: $50 \%$, Cell temperature: $70{ }^{\circ} \mathrm{C}$. $\mathrm{Tda}=\mathrm{Tdc}=65^{\circ} \mathrm{C}$. ally occurred in the cathode since, as shown in Fig.4, the oxygen gain increased and oscillations in the cell voltage were observed when the current density was increased

\section{Conclusion}

The distribution of water droplets in the cathode could be observed clearly and there was good agreement between the transition points to two-phase flow observed experimentally and those calculated using a two-dimensional model. Flooding occurred in the cathode at high current densities, although no water droplets were observed in the images obtained.

\section{Acknowledgement}

This work was supported by Research and Development of Polymer Electrolyte Fuel Cells from the New Energy and Industrial Technology Development Organization (NEDO), Japan and by the Open Research Center Project from the Ministry of Education, Culture, Sports, Science and Technology, Japan.

\section{References}

1) D. M. Bernardi and M. W. Verbrugge, J. Electrochem. Soc., 139, 2477 (1992)

2) T. E.Springer, T. A. ZAwodzinski, M. S. Wilson, and S. Gottesfeld, J. Electrochem. Soc., 143, 587 (1996)

3) T. V. Nguyen and R. E. White, J. Electrochem. Soc., 140, 2178, (1993)

4) T. Tüber, D. Pocza, and C. Hebling, J. Power Sources, 124, 403 (2003)

5) X. G. Yang, F. Y. Zhang, A. L. Lubawy, and C. Y. Wang, Electrochem. Solid State Lett., 7, A408(2004)

6) J. Zhang, D. Kramer, R. Shimoi, Y. Ono, E. Lehmann, A. Wokaun, K. Shinohara, and G. G.Scherer, Electrochim Acyta, 51, 2715 (2006)

7) F. Z. Zhang, X. G. Yang, and C. Y. Wang, J. Electrochem. Soc., 153, A225 (2006)

8) T. Murahashi, H. Hayashi, and E. Nishiyama The $11^{\text {th }}$ FCDIC Fuel Cell Symposium Proceedings, FCDIC, Tokyo (2004) pp111-116 [in Japanese]

9) T. Murahashi, M. Naiki, and E. Nishiyama, J. Power Sources, 162, 1130 (2006).

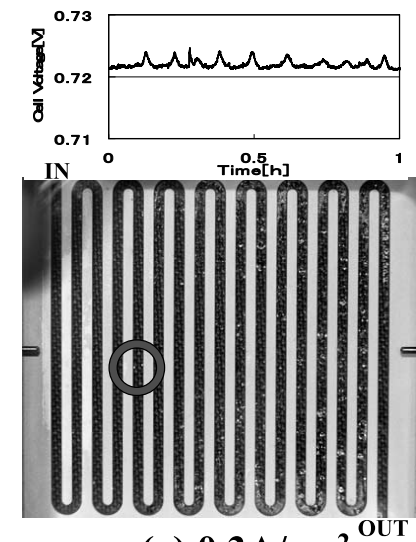

(a) $0.3 \mathrm{~A} / \mathrm{cm}^{2}$
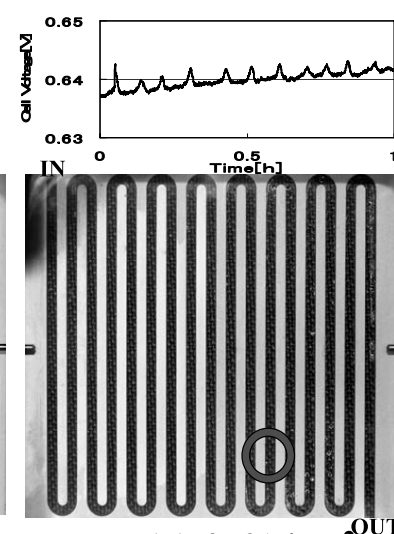

(b) $0.6 \mathrm{~A} / \mathrm{cm}^{2}$

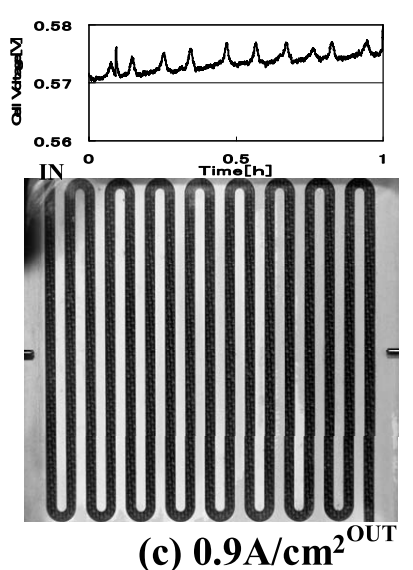

(c) $0.9 \mathrm{~A} / \mathrm{cm}^{2}$

Fig. 5 Visualized water droplets and current density. Upper graphs show the oscillations of cell voltage with time $\mathrm{H}_{2} /$ air, Uf: $70 \%$, Uo: $50 \%$, Cell temperature: $70{ }^{\circ} \mathrm{C} \mathrm{Tda}=\mathrm{Tdc}=65{ }^{\circ} \mathrm{C}$, (a) $0.3 \mathrm{~A} / \mathrm{cm}^{2}$, (b) $0.6 \mathrm{~A} / \mathrm{cm}^{2}$, (c) $0.9 \mathrm{~A} / \mathrm{cm}^{2}$ 